\title{
La alianza virtual. Razones del cambio en las elecciones presidenciales en el estado de México, 1999
}

\author{
Javier Arzuaga Magnoni* \\ Carlos Alberto Sara Gutiérrez**
}

\begin{abstract}
The paper takes up again a hypothesis previously presented, and the way it was refuted by the facts on July $2^{\text {nd }}, 2000$, when the federal presidential elections took place. In that previous paper it was stated that the division of the electoral offer in three choices -in the governor elections in Mexico state in 1999 favored the triumph of the Institutional Revolutionary Party as it fragmented the opposition vote and allowed this party to rest on its hard vote in order to win the elections. As a consequence of the new electoral scenario, this paper presents a complementary hypothesis to the one that suggests that in spite of the failure in articulating a big opposition alliance, this was actually articulated by the electorate. From a spatial analysis of the electorate the aim is observing if a transference of votes from the opposition to the option that was believed capable of defeating the ruling party actually took place.
\end{abstract}

Keywords: elections, Mexico state, political parties.

\section{Resumen}

El trabajo retoma una hipótesis postulada en un trabajo anterior y se plantea en qué medida fue refutada por los acontecimientos del 2 de julio de 2000, cuando se verificaron las elecciones federales a presidente de la república. En dicho trabajo se planteaba que la división de la oferta electoral en tres opciones, en la elección para gobernador del estado de México en 1999, favoreció el triunfo del Partido Revolucionario Institucional al fragmentar el voto opositor y permitir que a ese partido le alcanzara con recostarse sobre su voto duro para imponerse en los comicios mencionados. Como consecuencia del nuevo escenario electoral, se postula aquí una hipótesis complementaria de aquella que sostiene que a pesar del fracaso del intento formal por constituir una única gran alianza, ésta fue generada por el electorado. A partir de un análisis espacial de los resultados electorales se pretende observar si ocurrió efectivamente una transferencia de votos opositores hacia la opción que se creía podía derrotar al PRI.

Palabras clave: elecciones, estado de México, partidos políticos.

* Universidad Autónoma del Estado de México. Correo-e: jaam@uaemex.mx

** Universidad Autónoma del Estado de México. Correo-e: sagc@uaemex.mx 


\section{Introducción}

En un trabajo anterior (Arzuaga, 1999), en el que se analizaron los resultados de la elección de gobernador del estado de México en 1999, se postuló la hipótesis de que la división en tres de la oferta electoral favoreció el triunfo del Partido Revolucionario Institucional (PRI), al fragmentar el voto opositor y permitir que a ese partido le alcanzara con recostarse sobre su voto duro para imponerse en los comicios mencionados.

De cara a la elección presidencial de 2000, y ante el frustrado intento de congregar a los partidos políticos opositores al PRI en una única gran coalición, el escenario electoral se percibía, en la entidad, poco propicio para el cambio y la alternancia. En el trabajo mencionado se sugirió que sólo una amplia alianza que pudiera dividir la oferta electoral en dos podía propinar una derrota al PRI.

A pesar de que se volvía a producir una competencia electoral en la que la oferta se presentaba segmentada en tres grandes posiciones (con el PRI como uno de los contendientes y dos alianza parciales muy similares a las de la elección de gobernador de 1999), los resultados de la elección presidencial de 2000 refutaron la hipótesis manejada en aquella ocasión.

La pregunta que se plantea en este trabajo es en qué medida la hipótesis referida fue refutada por los acontecimientos del 2 de julio de 2000. Y se manejará una hipótesis complementaria de aquélla, que sostiene que a pesar del fracaso del intento formal por constituir una única gran alianza, ésta fue generada por el electorado, el cual en la práctica tendió a dividirse en dos.

Para demostrar la hipótesis propuesta, se recurrirá a un análisis espacial de los resultados electorales, a partir del cual se pretende observar si ocurrió efectivamente una transferencia de votos opositores hacia la opción que se creía podía derrotar al PRI.

\section{Competitividad y márgenes de victoria}

Separadas por sólo 363 días, entre la elección de gobernador de 1999 y la presidencial de 2000 se produjeron diferencias notables. Baste recordar que el PRI perdió, en esos días, 11 puntos porcentuales, 8 de los cuales los acaparó la Alianza por el Cambio $^{1}$ para imponerse por primera vez en la entidad (véase el cuadro 1). 
Estas modificaciones porcentuales, incluida la de la Alianza por México, ${ }^{2}$ que perdió poco menos de tres puntos, fue, en buena medida, el resultado de la competencia de los tres contendientes mencionados, por los votos adicionales provenientes de un leve crecimiento en la lista nominal de electores -un total de 433,472 electores más en la elección presidencial de 2000- (véase el cuadro 2) y una mayor participación ciudadana (de $47.2 \%$ a 67.9\%).

Ambos acontecimientos incrementaron el número total de votos de 3’358,628 en la elección de gobernador de 1999 a 5'124,572 en la elección presidencial de 2000, es decir, un aumento de 1'765,944 votos. De éstos, 1'057,542 se los adjudicó la Alianza por el Cambio, 224,083 el PRI, 217,881 la Alianza por México y el resto se lo repartieron otras denominaciones menores (véase el cuadro 2).

Ahora bien, frente a la propuesta de análisis formulada, cabe preguntarse si, como consecuencia de los cambios reseñados, se dividió el electorado en dos.

Una primera inspección de los resultados electorales en la entidad muestra que, desde las elecciones de ayuntamientos de 1996, el rango de resultados de los partidos políticos que se ubican en primero, segundo y tercer lugares, independientemente de la denominación política específica de los partidos que ocuparon dichos lugares, se mantiene estable (véase el cuadro 3).

Los valores específicos alcanzados por el primer lugar se ubican entre $44.5 \%$ que obtuvo la Alianza por el Cambio en la elección presidencial de 2000 y 34.6\% que cosechó el PRI en la elección de senadores de 1997. La variación en los extremos, como puede verse, es de prácticamente diez puntos porcentuales.

Más estrechos, sin embargo, fueron los márgenes en que se movieron los resultados de los segundos y terceros lugares. Aquellos lo hicieron entre 35.5\% alcanzado por el PAN en la elección de gobernador de 1999 y $30.2 \%$ del mismo partido en las elecciones de diputados locales de 1996. Estos últimos, los terceros,

${ }^{1}$ La Alianza por el Cambio la formaron el Partido Acción Nacional (PAN) y el Partido Verde Ecologista Mexicano (PVEM), los cuales en la elección de gobernador de 1999 compitieron con otra denominación (Coalición PAN/PVEM), aunque estuvo constituida por los mismos partidos.

${ }^{2}$ La Alianza por México estuvo conformada por el Partido de la Revolución Democrática (PRD), el Partido del Trabajo (PT), el Partido de la Sociedad Nacionalista (PSN), el Partido Convergencia por la Democracia (CD) y el Partido Alianza Social (PAS); para los fines de este trabajo se la toma como equivalente de la Coalición PRT/PT que participó en la elección de gobernador de 1999 debido a que el aporte de los otros partidos no incluidos en 1999 es muy pequeño. 
entre 22\% de la Coalición PRD/PT en la elección de gobernador de 1999 y 19.1\% obtenido por la Alianza por México en la elección presidencial de 2000. De este modo, el rango de los resultados de los segundos lugares es de $5.3 \%$ y el de los terceros de $2.9 \%$.

Un indicador muy sencillo de competitividad electoral, el margen de victoria, ${ }^{3}$ ilustra algunos aspectos adicionales de dicha estabilidad. La diferencia entre primero y segundo, con variaciones importantes, se mantuvo en valores de dos dígitos hasta 1996; a partir de allí la norma ubica el margen de victoria en valores inferiores a los ocho puntos porcentuales. La única excepción a esta norma la constituye la elección presidencial de 2000, que alcanzó $12 \%$, casi cinco puntos por encima no sólo de los resultados de la etapa, sino que distanciado en igual proporción de los otros comicios que se celebraron simultáneamente en la entidad (véase el cuadro 3).

La distancia entre segundo y tercero y entre primero y tercero lugares, abusando del uso del margen de victoria, muestra elementos adicionales de interés. Una primera cuestión resulta clara, en oposición a lo sucedido entre primero y segundo lugares, ya que la diferencia entre segundo y tercero ha sido originalmente pequeña y ha tendido a incrementarse. Una explicación breve puede dirigirse a que en tiempos del partido dominante las diferencias entre primero y segundo eran tan grandes que no había espacio para una gran distancia entre segundo y tercero. De hecho, se puede mostrar, a la inversa, que entre 1981 y 2000 las diferencias entre segundo y tercero se hacen mayores cuando menores son las distancias entre primero y segundo. No obstante que aumenta la competitividad, el ritmo de acercamiento es desigual, y es mayor entre primero y segundo lugares y menor entre primero y tercero lugares (véase el cuadro 3).

Una segunda observación sirve para distinguir que, desde 1996, las distancias entre primero y tercero se encuentran entre $15 \%$ y $20 \%$, nuevamente con la excepción de la elección presidencial de 2000, que es de $25.4 \%$ (véase el cuadro 3 ).

Por último, cabe resaltar que la variabilidad entre los distintos valores, tanto del margen de victoria como entre los tres primeros lugares son, a partir de 1996, muy pequeños: de 5\% entre primero y segundo, de $5.8 \%$ entre segundo y tercero y de $10.8 \%$ entre primero y tercero lugares, lo que confirma la estabilidad de la competitividad en el periodo (véase el cuadro 3).

\footnotetext{
${ }_{3}^{3}$ Para una explicación muy didáctica de su uso véase Villarreal y Gómez (2000).
} 
Lo dicho hasta aquí tiende a indicar que desde 1996 se ha estabilizado la oferta electoral en tres opciones. La aplicación del indice $\mathrm{N},{ }^{4}$ un indicador de competitividad electoral más eficaz y sintético, confirma esta premisa. Los valores que asume $\mathrm{N}$ entre 1996 y 2000 se encuentran entre 2.8 y 3.6, lo cual indica la existencia de una competencia entre tripartidista y un poco más (véase el cuadro 3).

A pesar de ello, los márgenes entre las distintas elecciones permite concluir que, aunque la competencia se muestra tripartidista en el final de siglo, la elección presidencial de 2000 fue la que mayor dispersión mostró en los primeros lugares. Lo cual si bien no llegó a dividir el electorado en dos, se trató de la menos tripartidista de las últimas elecciones. Los cambios que se dieron fueron, pues, marginales, pero frente a lo cerrado de la competencia electoral, también decisivos.

\section{Competencia en el ámbito municipal}

El carácter marginal del cambio puede observarse, también, a partir de los elementos en común. Los resultados del 4 de julio de 1999 y los del 2 de julio de 2000 (por tomar sólo los eventos que originaron este análisis) conservan patrones comunes ${ }^{5}$ que será necesario abordar.

La candidatura priísta obtuvo el triunfo, en la elección de gobernador de 1999, en 100 de los 122 municipios que componen la entidad. De esos 100 triunfos, nueve se ubicaron en la región nororiente (NO) ${ }^{6}$ del estado de México, 17 en la zona me-

${ }^{4}$ El índice $\mathrm{N}$ adopta valores que representan el número de partidos en competencia efectiva. Su fórmula es: $N=\frac{1}{\sum P i^{2}}$, donde $\mathrm{P}_{\mathrm{i}}$ es la proporción de votos de cada partido (Taagepera y Shugart, 1989).

${ }^{5}$ Por patrones comunes se hace referencia a pautas de distribución geográfica de los votos que, como lo afirman muchas investigaciones, se asocian con estructuras sociodemográficas específicas. Los municipios en los que se impone el PRI son fundamentalmente rurales y en ellos, es sabido, habitan los sectores más desprotegidos y marginados de la sociedad mexiquense. La aplicación del coeficiente $r$ de Pearson entre algunas variables sociodemográficas y la votación porcentual por el PRI otorgan pruebas contundentes: el coeficiente adopta valores fuertemente positivos con el analfabetismo, la dotación de servicios a las viviendas y la ruralidad. Para las coaliciones opositoras, los resultados obtenidos son exactamente los contrarios, con más fuerza en el caso del PAN/ PVEM que en el del PRD/PT. Aunque en esta ocasión se referirán a los casos en cuestión, se trata de patrones que observan una larga trayectoria (Molinar, 1991; Emmerich, 1993 y Emmerich, 1999).

${ }^{6}$ La entidad fue fraccionada en seis regiones. Esta regionalización surgió de dividir al Estado de México en cuatro cuadrantes y separar, al mismo tiempo, las zonas metropolitanas tal como las define el Instituto Nacional de Estadística, Geografía e Informática. Los resultados de ambas operaciones aparecen en el mapa I y los nombres de los municipios que componen cada región pueden verse en el cuadro 4 . 
tropolitana del Valle de México (ZMVM), 27 en la región norponiente (NP), 33 en la surponiente (SP), 5 en la zona metropolitana Toluca/Lerma (ZMTL) y 9 en la región suroriente (so). Es decir, $60 \%$ de los municipios en los que se impuso el PRI provenían del poniente de la entidad (véanse el mapa II y el cuadro 5).

\section{Mapa I}

Regiones electorales del estado de México

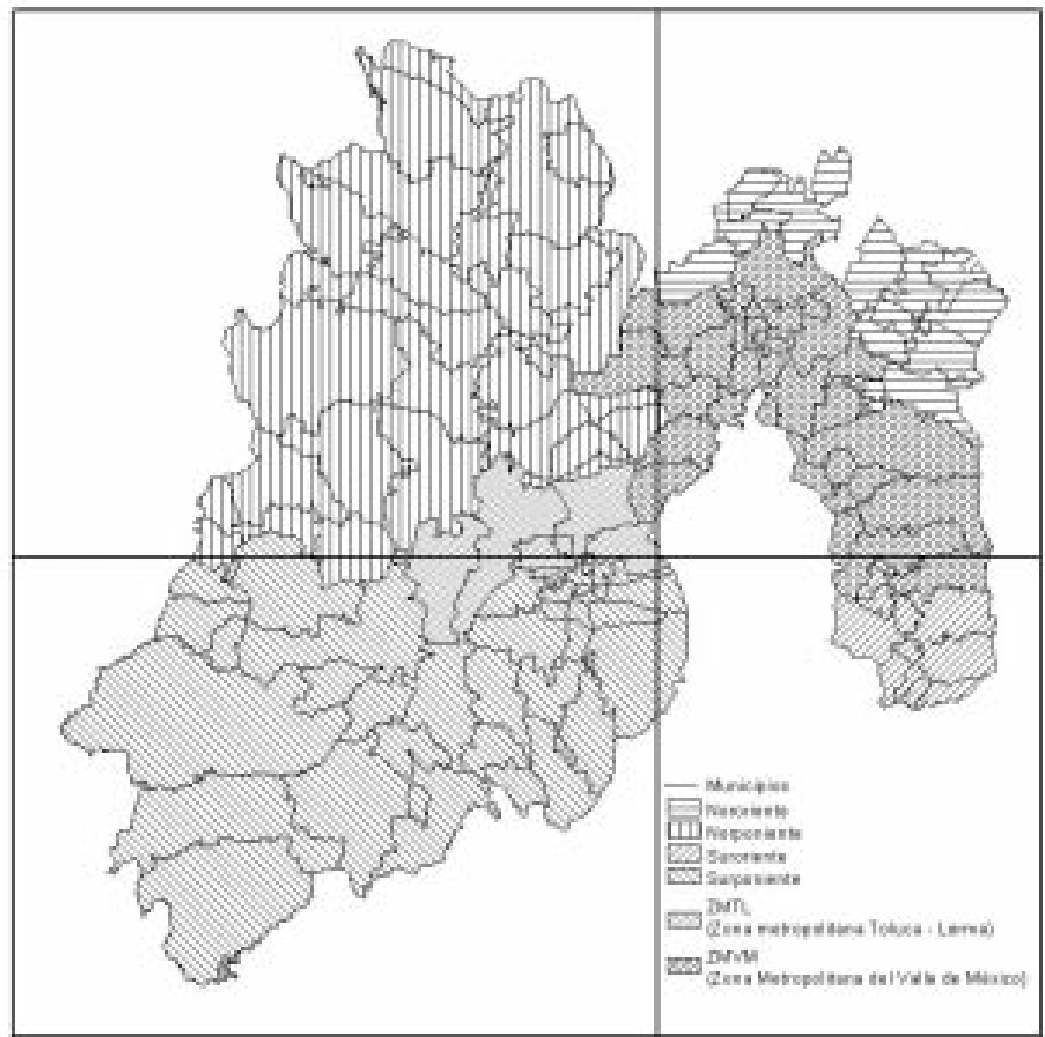




\section{Mapa II}

Elección de gobernador de 1999 por partido ganador

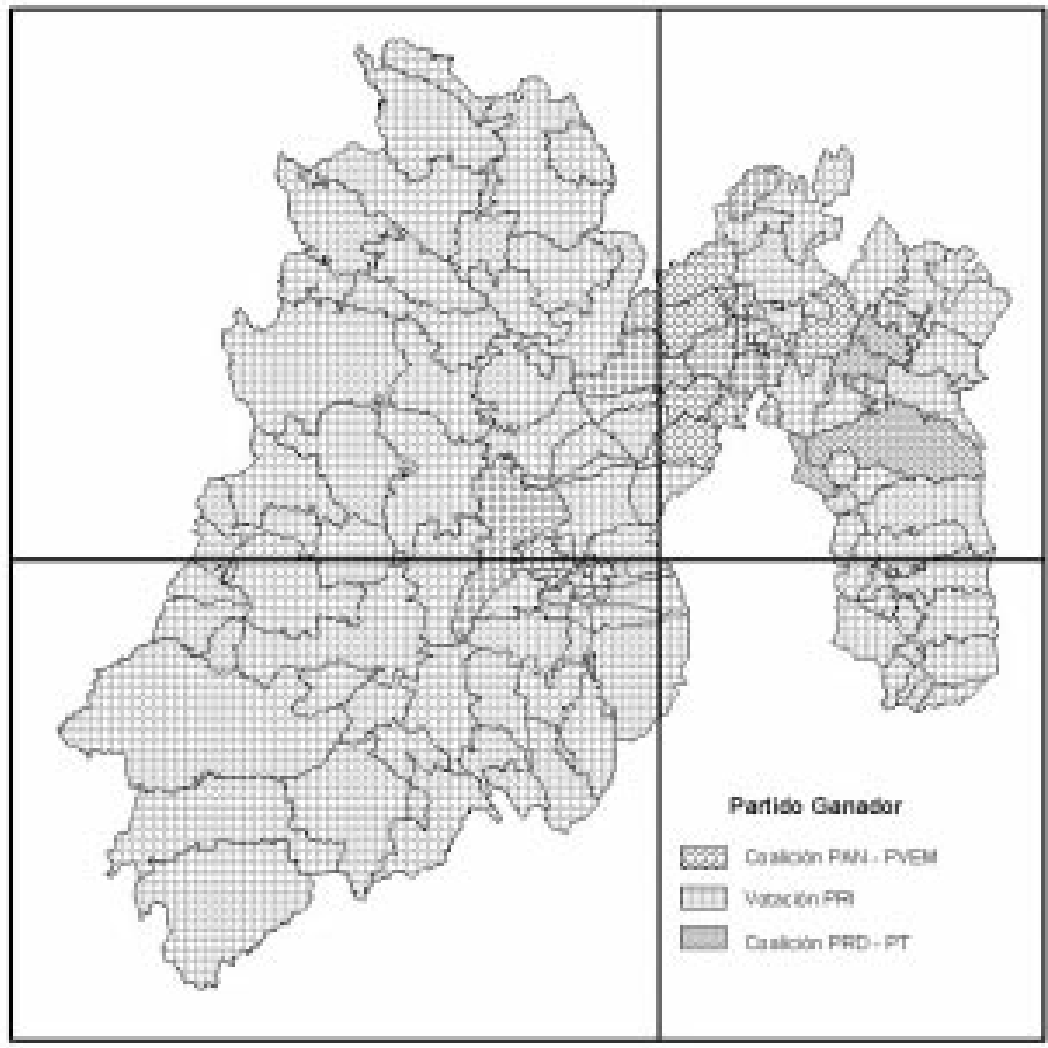

En la elección presidencial de 2000 el PRI se impuso sólo en 65 municipios, y la distribución de los mismos fue la siguiente: 6 en la región NO, 5 en la ZMVM, 24 en la región NP, 23 en la región sP y 7 en la región so. Los municipios en que se impuso en las zonas metropolitanas se redujo a sólo 15\% de los del Valle de México y fue nula en la del valle de Toluca. En contraparte, los municipios del poniente de la entidad le otorgaron $72.3 \%$ de sus triunfos en el ámbito municipal (véanse el mapa III y el cuadro 5). 


\section{Mapa III \\ Elección presidencial del 2000 por partido ganador}

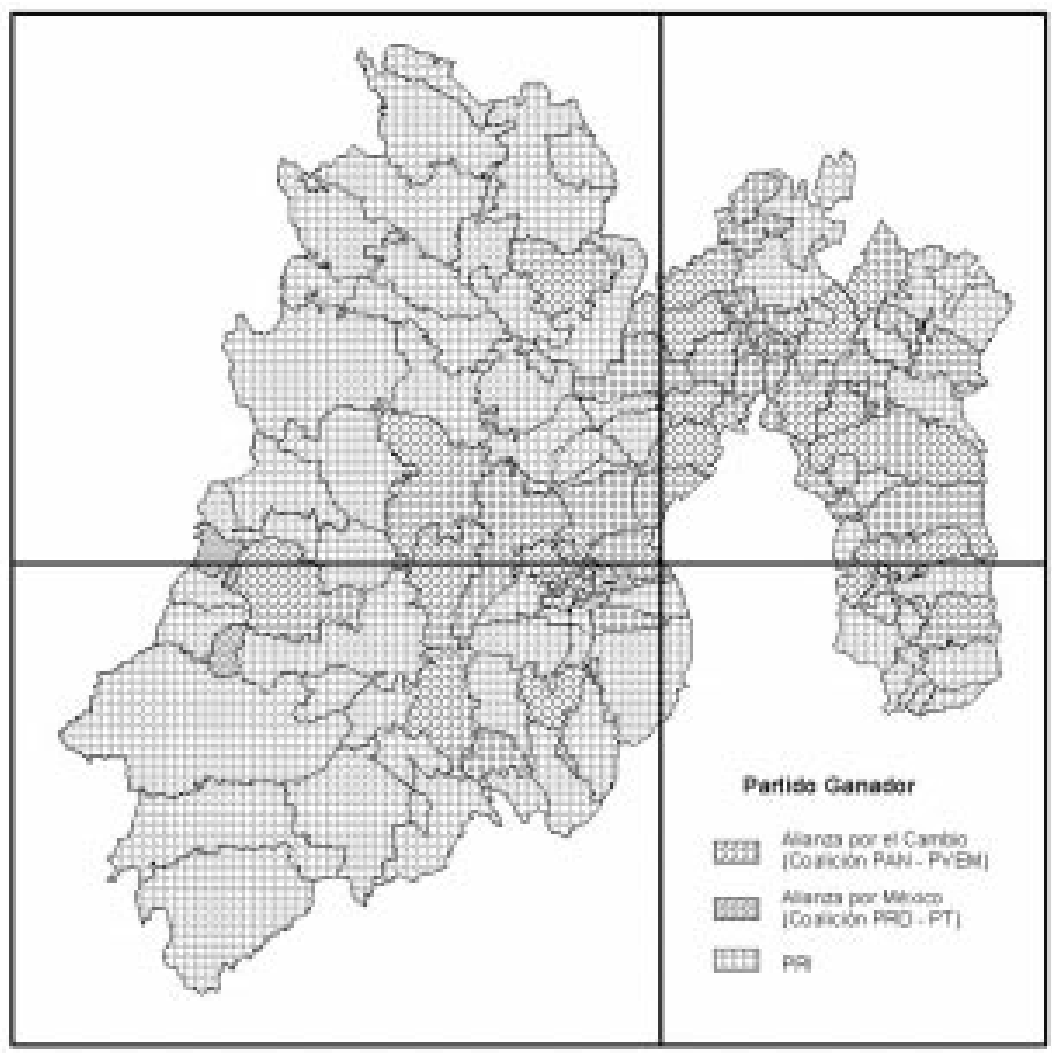

Entre una elección y otra, el PRI conservó, pues, una distribución territorial similar, aunque dependió más de los triunfos en el poniente de la entidad y menos de los de las zonas metropolitanas.

La Coalición PAN/PVEM, por su parte, se impuso en la elección de gobernador de 1999 en 17 municipios de la entidad, los cuales se distribuyeron de la siguiente manera: 3 en la región No, 11 en la ZMVM, 2 en la ZMTL y 1 en la región so. En las regiones con mayor presencia priísta (NP y SP) dicha alianza no consiguió triunfo alguno (véanse el mapa II y el cuadro 5). En este caso, las variaciones sobre la pauta se refieren más a la flexibilización de los patrones que, como en el caso del PRI, a su radicalización.

En la elección presidencial de 2000 el número de municipios donde se impuso la Alianza por el Cambio se incrementó a 55. De ellos, 7 provinieron de la región NO, 27 de la ZMVM, 2 de la región NP, 9 de la región sP, 7 de la ZMTL y 3 de la región so. Así, 
mientras las dos zonas metropolitanas le aportaban a dicha alianza $76.5 \%$ de los municipios en que se impuso en 1999, en 2000 aportaban $61.8 \%$ (véanse el mapa III y el cuadro 5).

La Coalición PRD/PT, por último, obtuvo el triunfo en la elección de gobernador de 1999 en cinco municipios, de los cuales uno provino de la región No y cuatro de la ZMvM. En la elección presidencial de 2000, el número total de municipios donde ganó la Alianza por México fue de dos, localizados en las regiones NP y SP (véanse el mapa III y el cuadro 5), con lo que se desvaneció toda pauta geográfica fundada en este criterio.

Resulta oportuno, en este punto, reseñar algunos elementos para el análisis. La Alianza por el Cambio incrementa el número de triunfos obtenidos por la Coalición PAN/PVEM en el ámbito municipal en 38 , de los cuales 21 provienen de las zonas metropolitanas. Esos 21 habían sido conseguidos en la elección de gobernador de 1999 por el PRI (17) y por la Coalición PRD/PT (4). Doce de los 17 triunfos prí́stas y los cuatro perredistas provenían de la ZMVM.

A pesar de ello, la Alianza por el Cambio amplía su presencia en otras regiones de la entidad: crece en 17 el número de municipios en que triunfa. No obstante, se impone en municipios que suelen ser colindantes con las zonas metropolitanas.

\section{Competencia en el ámbito regional}

Si se cambia la unidad de análisis y en lugar de observar el número de municipios en que triunfa cada opción política se estudia el porcentaje de votos por partido, coalición o alianza en el ámbito regional, se tiene que el PRI en 1999 se impuso en 5 de las 6 regiones de la entidad. Sus márgenes de victoria van desde $43.4 \%$ en la región NP a 1.8\% en la ZMTL. Sólo pierde en la ZMVM, aunque se trata, en realidad, de un virtual empate (véase el cuadro 6). A pesar de su triunfo en la mayor parte de las regiones del estado, el PRI tiende a decrecer su votación porcentual en las zonas metropolitanas (véase el mapa IV). 


\section{Mapa IV}

Votación por partido en la elección de gobernador en 1999 y $\%$ de votación del PRI, por región

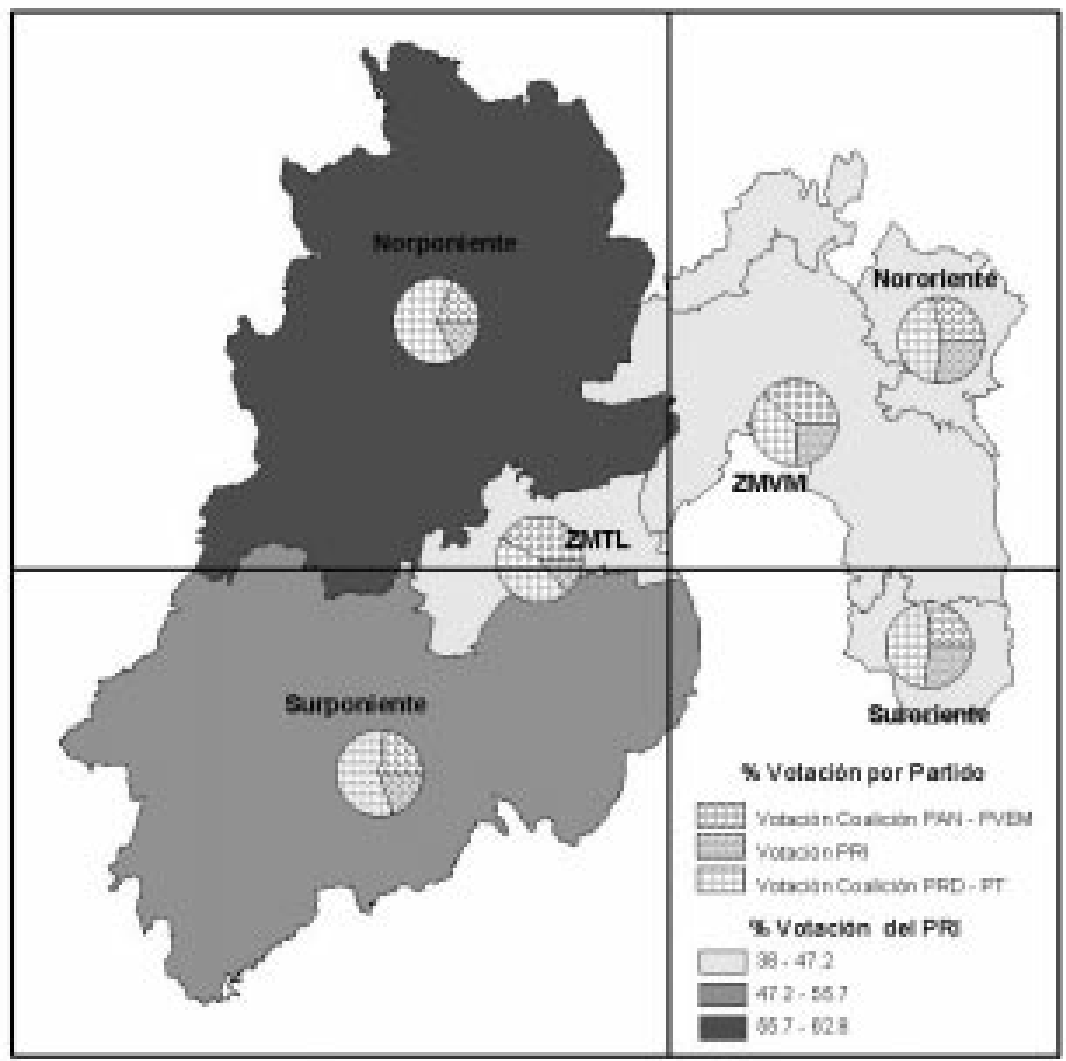

Lo dicho se confirma en la elección presidencial de 2000 (véase el cuadro 7). En ella el PRI se impone en sólo tres de las 6 regiones de la entidad y pierde ampliamente en las zonas metropolitanas. Sus márgenes de victoria son del orden de $4.4 \%$ a $15.2 \%$ (véase el mapa VII).

Los triunfos de la Coalición PAN/PVEM y de la Alianza por el Cambio se registran en la ZMVM en la elección de gobernador de 1999 y en la región NO, en la ZMVM y en la ZMTL en la elección presidencial de 2000. Cabe destacar que mientras que se encuentra menos de un punto porcentual por encima del PRI en la primera de las dos zonas metropolitanas mencionadas en 1999, en la elección presidencial de 2000 lo hace por más de 15\%. Su situación en la ZMTL cambió, ya que después de situarse abajo del PRI en casi $2 \%$ se ubicó por arriba de dicho partido en más de $15 \%$ (véanse los mapas V y VIII). 


\section{Mapa V}

Votación por partido en la elección de gobernador en 1999 y \% de votación de la coalición PAN-PVEM, por región

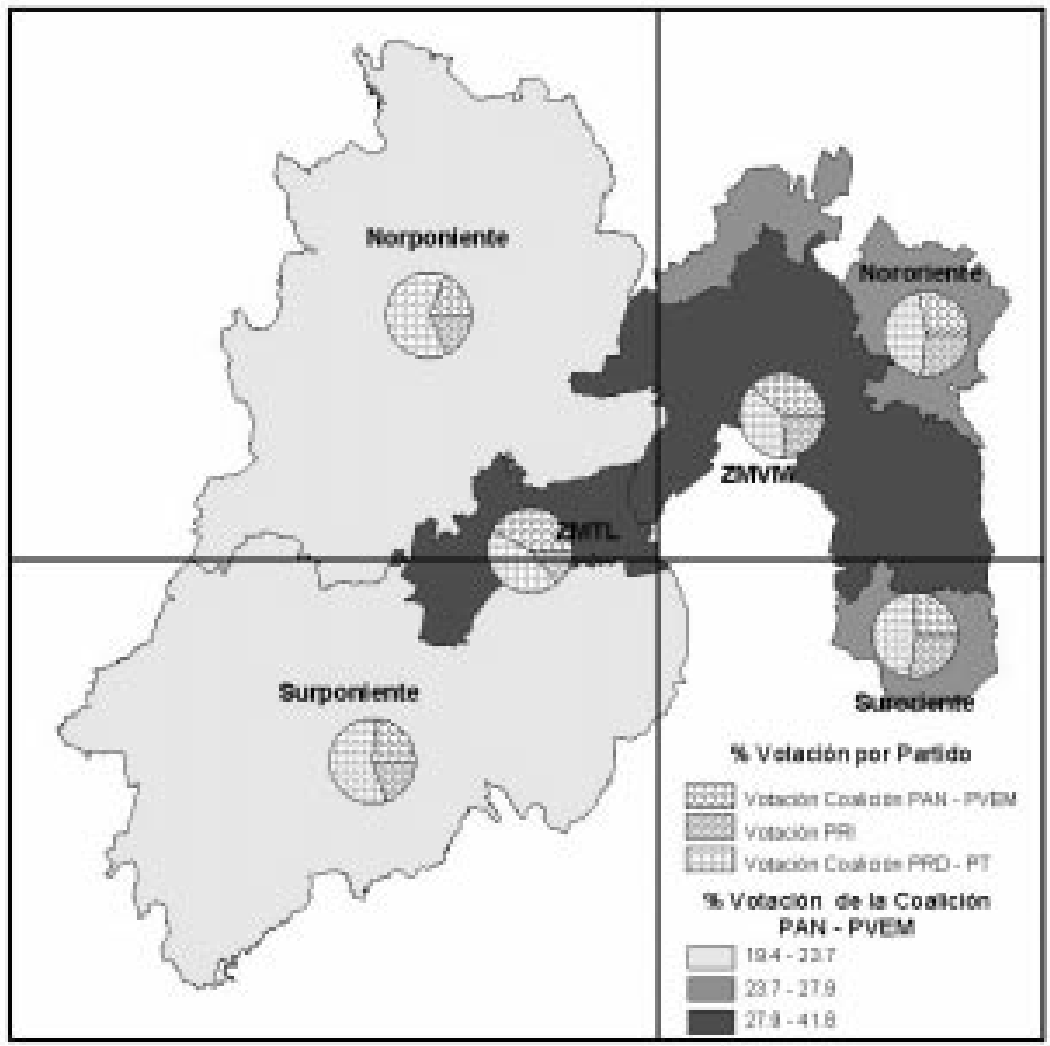

Los cambios son, retomando lo dicho, no sólo marginales respecto de sus antecedentes inmediatos sino que, además, están territorialmente concentrados: se trata de alteraciones marginales en las zonas metropolitanas.

\section{5. Ámbitos rural y urbano: la ventaja del PRI}

Hasta 1999 todo hacía pensar que en la segunda entidad federativa más industrializada del país el PRI ganaba con el voto de los municipios rurales. ¿Cómo era esto posible? ¿En los municipios metropolitanos de la entidad vivía 79.6\% de la población total del estado de México, y a pesar de ello el PRI ganaba con el voto rural? Está claro que esto no era posible, que las matemáticas jugaban aquí una trampa. Al utilizar los resultados porcentuales a la hora de los cálculos se igualan municipios de tamaños muy 


\section{Mapa VI}

Votación por partido en la elección de gobernador en 1999 y $\%$ de votación de la coalición PRD-PT, por región

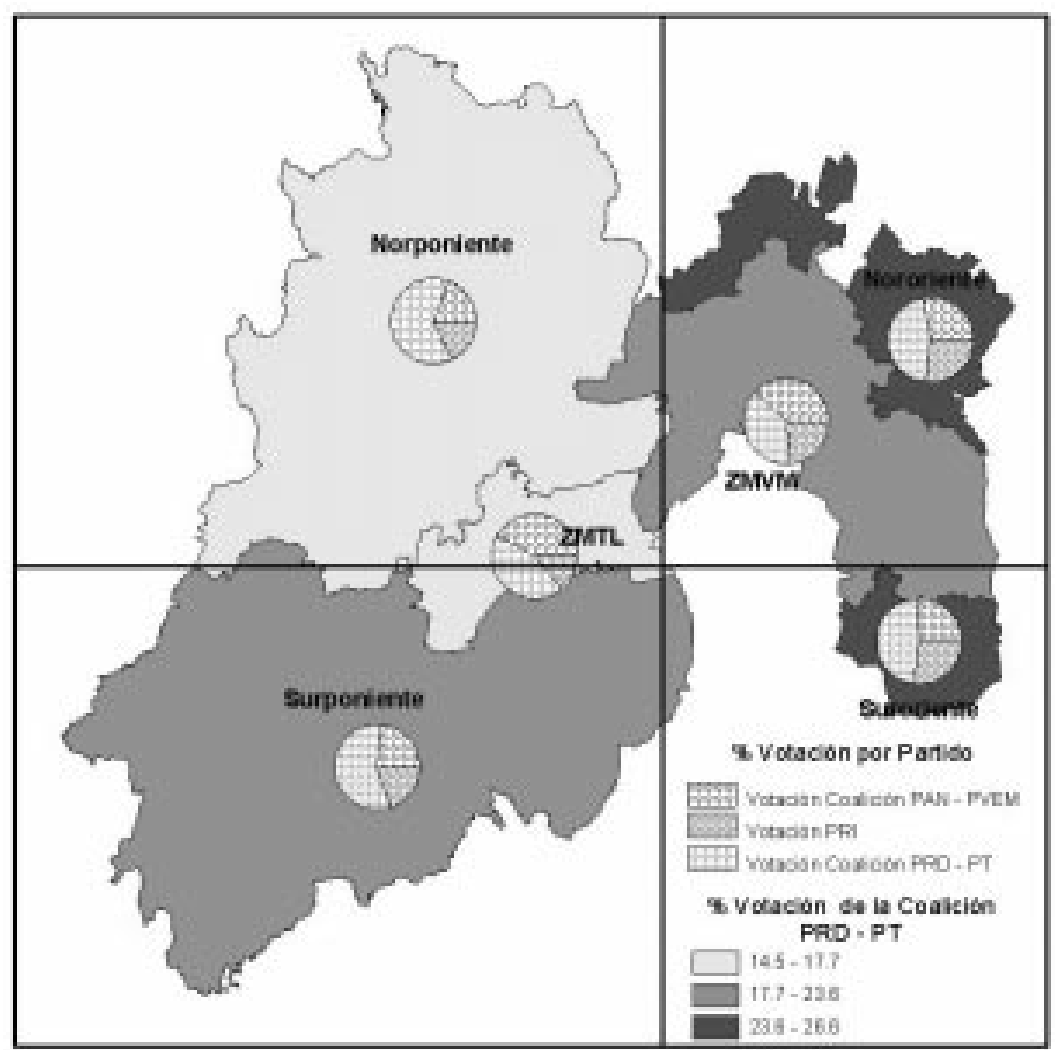

diversos. Sin embargo, la afirmación no era del todo falsa. Antes bien era, para 1999, considerablemente cierta.

En efecto, si los comicios se hubiesen desarrollado únicamente en los municipios metropolitanos del estado de México, el PRI hubiese perdido la elección de gobernador de 1999; los votos provenientes de los municipios rurales le permitieron alcanzar la diferencia a su favor.

En los 39 municipios metropolitanos el PRI obtuvo 1’005,680 votos, 38.7\% de los emitidos válidos, y se colocó en estas dos regiones casi cuatro puntos porcentuales por debajo de su media estatal. En cambio, de los restantes 651,290 votos emitidos en las regiones no metropolitanas de la entidad, el PRI se alzó con 373,548 votos, $57.4 \%$ de los emitidos válidos, casi 15 puntos porcentuales por encima de su media estatal y casi 19 


\section{Mapa VII}

Votación por partido en la elección presidencial en 2000 y \% de votación del PRI

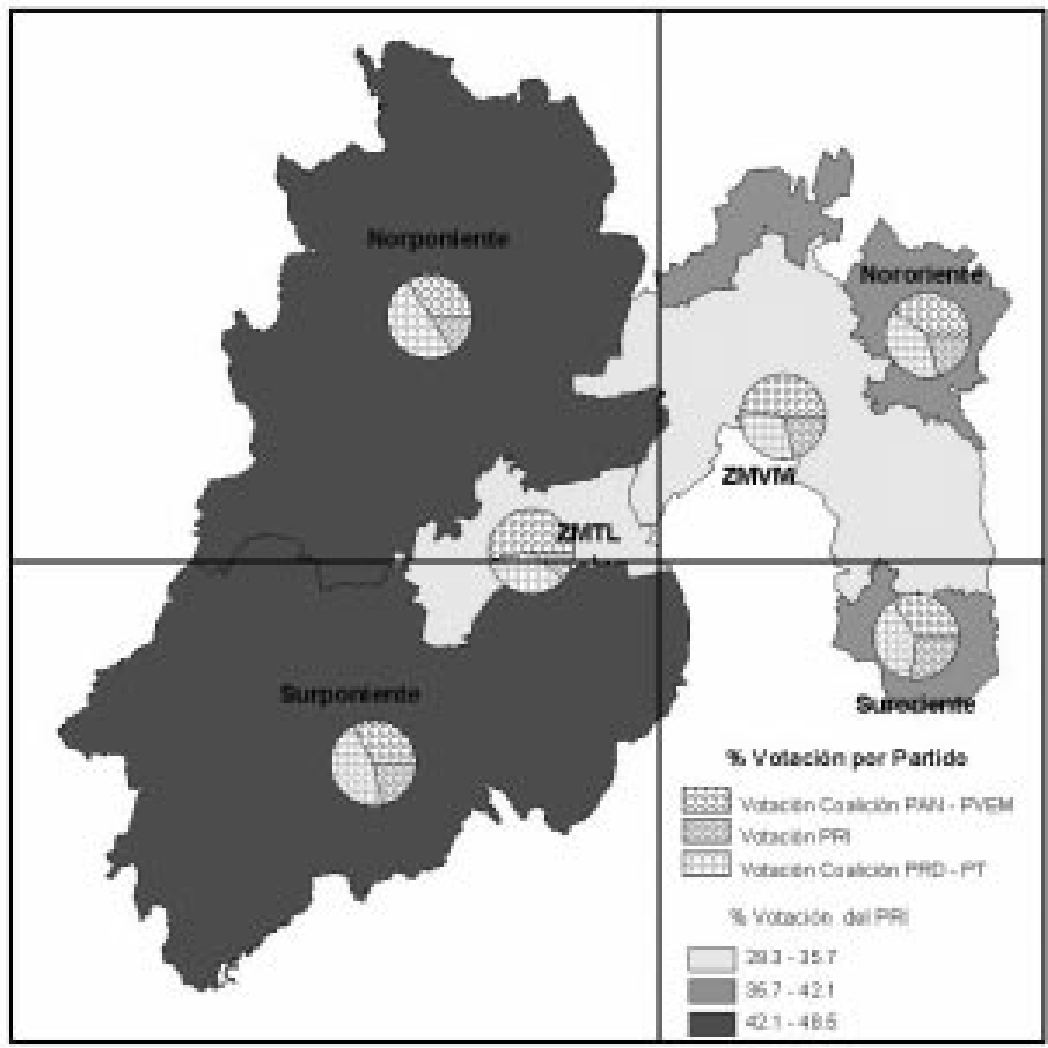

respecto del porcentaje obtenido en las zonas metropolitanas (véanse los cuadros 6 y 7).

La Coalición PAN/PVEM, por su parte, alcanzó en esos 39 municipios 1'006,442 votos, 38.7\% de los emitidos válidos en la elección de gobernador de 1999, consiguiendo en las dos zonas poco más de 3 puntos porcentuales por encima de su media estatal. Por el contrario, consiguió en el resto de la entidad 145,072 votos, $22.3 \%$ de los emitidos válidos, es decir, más de 13 puntos porcentuales por debajo de su media estatal y más de 16 con relación a las áreas urbanas de los valles de México y Toluca (véanse los cuadros 6 y 7).

Entre ambos, pues, se produjo un virtual empate en las zonas metropolitanas; la diferencia a favor de la Coalición PAN/PVEM es de sólo $0.03 \%$, mientras que en el resto de la entidad la diferencia se agiganta en favor del PRI a 35.08\%. 


\section{Mapa VIII}

Votación por partido en la lección presidencial en 2000 y $\%$ de votación de la Alianza por el cambio (PAN-PVEM)

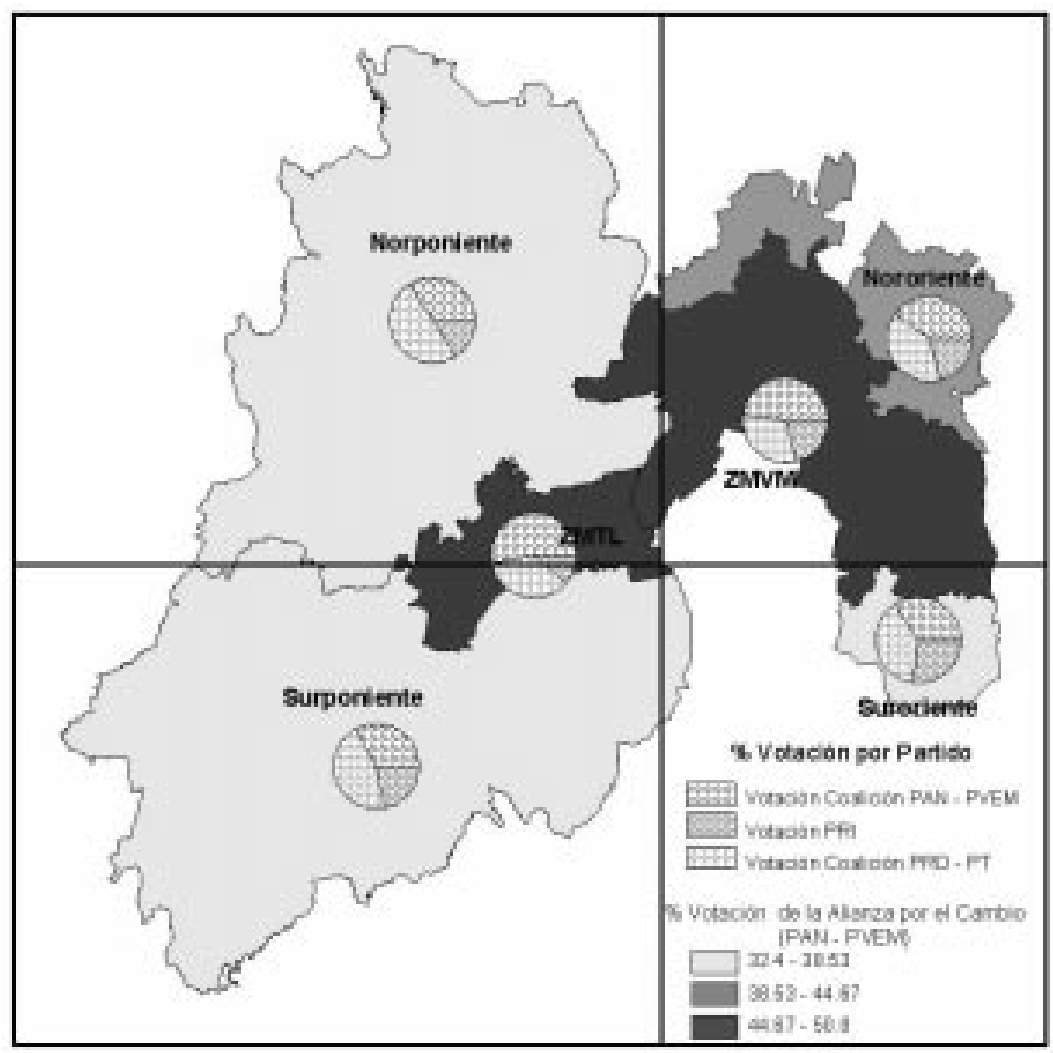

Con 583,158 votos en las dos zonas metropolitanas, $22.45 \%$ de los válidos emitidos, la Coalición PRD/PT no parece haber tenido diferencias sustanciales, en términos relativos, entre los resultados obtenidos en los municipios metropolitanos y los no metropolitanos. La diferencia porcentual entre los dos tipos de municipios supera apenas los dos puntos porcentuales, por lo que puede suponerse que la convocatoria de esta coalición tuvo en ellos un impacto similar (véanse los cuadros 6 y 7).

La conjugación correcta de la afirmación que se planteó al inicio de esta sección es, entonces, que el PRI ganaba con los votos rurales siempre que garantizara en las zonas metropolitanas un determinado piso electoral. Para describir la composición de ese piso resulta conveniente analizar los resultados obtenidos por dicho partido en las zonas metropolitanas. 
Sería un error considerar a estas zonas como homogéneamente pobladas y urbanas. Desde el punto de vista del número de habitantes que residen en cada municipio, entre Ecatepec, el más poblado, y Mexicalcingo, el menos poblado, media una diferencia de 1'448,462 personas. Por su parte, en relación con el porcentaje de población no urbana, el rango varía entre el 0\% de La Paz y Nezahualcóyotl y el 54\% de Atenco.

Si se divide el universo de los municipios metropolitanos en dos, notamos que el PRI triunfó en $68 \%$ de los municipios más pequeños y menos urbanos, mientras que de los más grandes y urbanos sólo logró obtener 40\%.

En síntesis, los municipios metropolitanos y no metropolitanos menos urbanos y más rurales le otorgan a PRI 621,703 votos por 360,510 de la coalición PAN/PVEM. La proporción es prácticamente 2 a 1 y la diferencia entre ambos, casi igual a la de los resultados para todo el estado. El 45\% de los sufragios que estos municipios le aportan a la votación priísta es sorprendentemente alto para una entidad federativa con más de $80 \%$ de su población urbana.

\section{Coaliciones en competencia y fragmentación del voto}

De todos modos se trataba de un piso que se iba achicando. La fragmentación del voto entre las dos coaliciones (PAN/PVEM y PRD/ РT) parece haber jugado un papel igualmente decisivo, inclinando la balanza en favor del PRI en la elección de gobernador de 1999.

En los 122 municipios que componen la entidad, los porcentajes de votación alcanzados por el PRI se ubicaron en esos comicios en un rango que iba desde $29 \%$ hasta $74.2 \%$. Es decir, en la práctica las dos coaliciones tenían para repartir, cuando mucho, dos tercios de la votación. La forma en que se repartieran este resto daría la oportunidad de imponerse o no imponerse al PRI. Y parece que los dividieron para perder.

El PRI no quedó tercero en ningún municipio. Por lo que en virtud de su mínimo de un tercio de votos, para poder perder era necesario que el resto de los votos no se distribuyeran uniformemente entre las otras dos opciones electorales.

Los resultados prueban este argumento. Si colocamos la diferencia entre las votaciones porcentuales de las dos coaliciones opositoras en cada municipio en rangos de diez puntos se puede apreciar que (véase el mapa IX): 


\section{Mapa IX \\ Fragmentación del voto opositor en 1999 y partido ganador en el 2000}

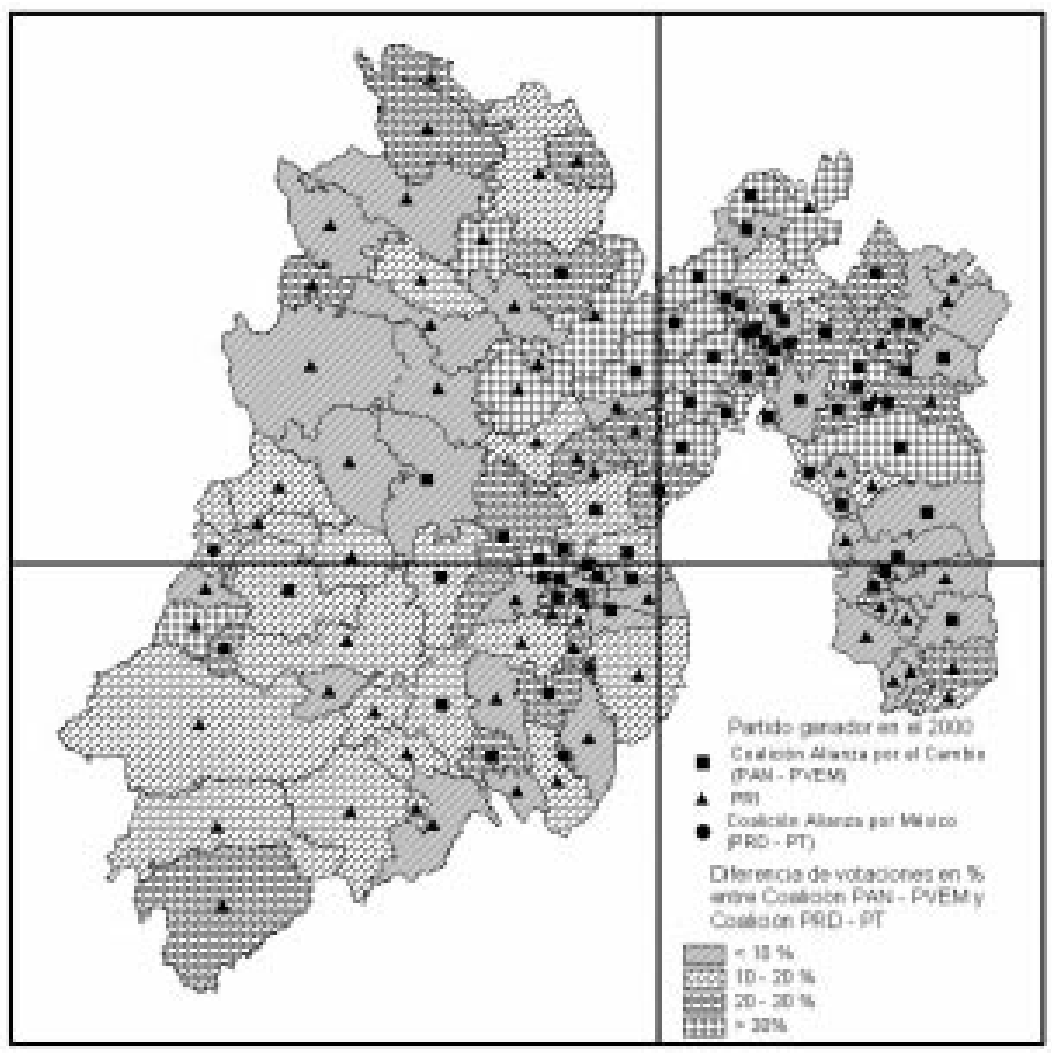

a) Cuando los votos no priístas se repartieron en proporciones cuya diferencia entre ambas era menor a $10 \%$ de los votos, esto sucedió en 44 casos, y sólo en un municipio se registró un triunfo opositor;

b) Cuando las proporciones estaban separadas entre diez y menos de veinte puntos porcentuales, es decir 31 casos, en dos municipios se impuso la oposición;

c) Cuando la diferencia se situaba entre veinte puntos y menos de treinta, es decir 29 casos, la oposición ganó en 7 municipios; y

d) Cuando la diferencia entre las coaliciones superó los treinta puntos, es decir 18 casos, la oposición triunfó en trece (véase el cuadro 6). 
Ahora bien, se trató de demostrar en el desarrollo del apartado anterior que el PRI obtuvo en la elección de gobernador de 1999 sus votos de los municipios con menor población y con mayor población rural. Igualmente se afirmó que esa relación se establecía con notoriedad en los municipios no metropolitanos y en una buena proporción de los metropolitanos.

Paralelamente, se sugirió que los votos opositores (fundamentalmente de la coalición PAN/PVEM) provenían de los municipios que tenían características contrarias a las indicadas. Diez municipios se ubican entre los que cumplen más cabalmente con esas tres características: Atizapán de Zaragoza, Coacalco, Cuautitlán Izcalli, Ecatepec, Metepec, Naucalpan, La Paz, Tecámac, Tlalnepantla y Tultitlán. Y fue precisamente en ellos donde la división del voto de las coaliciones opositoras se hizo más importante.

Si los votos de la coalición PRD/PT en esos municipios, y sólo los obtenidos en ellos, hubiesen sido trasladados a las cuentas de la coalición PAN/PVEM, el triunfo en la elección hubiese cambiado de manos.

\section{Las fuentes del cambio}

La situación, se dijo, cambia en parte en la elección presidencial de 2000. A continuación se tratará de demostrar que esos cambios marginales y metropolitanos provinieron de tres fuentes. La primera de ellas sugiere que la Alianza por el Cambio se impuso en aquellos municipios considerados perredistas. La segunda, que dicha Alianza triunfó en aquellos municipios en donde la fragmentación del voto opositor daba al PRI la oportunidad de imponerse. Y, por último, que los que no votaron en la elección de gobernador de 1999 lo hicieron por la Alianza por el Cambio, conformando, junto con los dos grupos de cuestiones anteriores la Alianza Virtual.

En la elección presidencial de 2000, el PRI consiguió en los 39 municipios metropolitanos 1'228,894 votos, 29.8\% de los emitidos válidos en los mismos, y se colocó poco menos de dos puntos porcentuales por debajo de su promedio estatal. La Alianza por el Cambio se alzó con 1'913,533 votos metropolitanos, $46.5 \%$, poco menos de tres puntos porcentuales por encima de la media en la entidad. La Alianza por México consiguió 788,273 votos en las zonas en cuestión, 19.1\%, y se ubicó aquí menos de un punto porcentual por encima de la media estatal. 
Los votos no metropolitanos, 1'007,057 en total, se repartieron en las siguientes proporciones: el PRI obtuvo $40.6 \%$, la Alianza por el Cambio $32.4 \%$ y la Alianza por México $17.2 \%$. De las tres ofertas electorales mencionadas, sólo el PRI se ubica en las regiones no metropolitanas por encima de la media estatal, 8.6 puntos arriba. Las otras dos opciones se encuentran $11.3 \%$ y $1.5 \%$ por debajo, respectivamente.

Si se comparan estos datos con los de la elección de gobernador de 1999 se tiene que las cosas no cambiaron demasiado en términos de los patrones mencionados. Los porcentajes obtenidos por las distintas ofertas electorales en las regiones metropolitanas y no metropolitanas se encuentran por arriba y por debajo de los promedios estatales en las mismas direcciones en las dos elecciones.

A pesar de ello, las que se han llamado fuentes del cambio ocurren principalmente en las zonas metropolitanas del estado de México, produciendo, al mismo tiempo, una confirmación de los patrones generales de comportamiento electoral en la entidad y una transformación que permitió a la Alianza por el Cambio imponerse.

La primera de esas fuentes, se dijo, fue la transferencia de votos en los municipios perredistas. Se tomarán tres indicadores para definir a los municipios perredistas. El primero de los indicadores consiste en considerar como perredistas a los municipios que al 2 de julio de 2000 eran gobernados por el PRD. El segundo de los indicadores permite denominar perredistas a los municipios en los que la Coalición PRD/PT se impuso en las elecciones de gobernador celebradas un año antes de la presidencial en cuestión. Y el último, define como perredistas a los municipios en los que el PRD se impuso en las elecciones de ayuntamientos celebradas simultáneamente con la presidencial de 2000.

En función del primer indicador, se tiene que el PRD gobernaba al 2 de julio de 2000 veinte municipios. De ellos, la Alianza por el Cambio se impuso en 7 , de los cuales 5 se ubican en la ZMVM. Dos de ellos son símbolos políticos del perredismo en la entidad, tanto por su importancia como porque se trata de municipios en donde el PRD se impone en ellos sistemáticamente desde 1996: Texcoco y Nezahualcóyotl.

De acuerdo con el segundo indicador, se puede observar que la Alianza por el Cambio triunfó en cuatro de los cinco municipios donde la Coalición PRD/PT ganó en la elección de gobernador de 1999. Todos ellos se ubican en la ZMVM y son todos los 
municipios metropolitanos en los que dicha coalición había ganado en la elección de gobernador.

Por último, la Alianza por el Cambio ganó en la elección presidencial de 2000 en ocho de los 15 municipios en los que la Alianza por México se impuso en la elección de ayuntamiento realizada simultáneamente. Cinco de ellos se ubican en la ZMVM. A cambio, la Alianza por México no se impuso en alguno de los municipios que podrían denominarse panistas utilizando los tres criterios anteriores.

La segunda fuente de cambio fue definida a partir del comportamiento de los denominados municipios con votos no priístas fragmentados. El grado de fragmentación se definió en categorías construidas a partir de la distancia que separa los porcentajes de votos por la Alianza por el Cambio y por la Alianza por México, ${ }^{7}$ como se hizo en páginas precedentes con la elección de gobernador de 1999.

Los resultados que muestra el grado de fragmentación en las elecciones presidenciales del año 2000 son los siguientes:

a) Cuando los votos por las alianzas mencionadas se repartieron en proporciones cuya diferencia entre ambas era menor a 10\% de los votos, esto sucedió en 26 casos, y se registraron cuatro triunfos de la Alianza por el Cambio;

b) Cuando las proporciones estaban separadas entre diez y menos de veinte puntos porcentuales, 29 casos, en once municipio se impuso la Alianza por el Cambio;

c) Cuando la diferencia se situaba entre veinte puntos y menos de treinta, 32 casos, la Alianza por el Cambio ganó en 14 municipios, $\mathrm{y}$

d) Cuando la diferencia entre las coaliciones superó los treinta puntos, 35 casos, la Alianza por el Cambio triunfó en 21 municipios y la Alianza por México en 2.

En comparación con lo sucedido en la elección de gobernador de 1999 se pueden observar algunas diferencias que implican un menor grado de fragmentación opositora, por un lado, y, por el otro, confirman la idea de que la menor fragmentación induce un mayor número de triunfos no priístas.

Para confirmar lo dicho se puede observar, en primer lugar, que los municipios con una alta fragmentación opositora re- 
presentaron 36.1\% en la elección de gobernador de 1999 y $21.3 \%$ en la elección presidencial de 2000; los de una fragmentación media alta, 24.6\% y 23.8\%; los de una fragmentación media baja, $23.8 \%$ y $26.2 \%$, y los de una baja fragmentación, $24.6 \%$ y $28.7 \%$.

En segundo lugar, que en los municipios con alta fragmentación los triunfos no priístas representaron $11.5 \%$ de los casos; en los de fragmentación media alta 37.9\%; en los de fragmentación media baja 43.8\% y en los de baja fragmentación $65.7 \%$.

Algunos datos adicionales sirven para confirmar lo sugerido. Entre la elección de gobernador de 1999 y la presencial de 2000 los municipios con alta fragmentación pasaron de 44 a 26. De los 18 municipios que redujeron el grado de fragmentación en 16 se impuso la Alianza por el Cambio. Asimismo, en diez municipios que redujeron su fragmentación de media alta a media baja o baja se impuso dicha Alianza. Por último, cabe destacar que la proporción de municipios metropolitanos que registraron una baja o media-baja fragmentación se incrementaron de 46.2\% en 1999 a 59\% en la elección presidencial de 2000 (véase el mapa IX).

La última fuente de cambio que se mencionó fue la incorporación de nuevos votantes, tanto por el crecimiento de la lista como por el incremento de la participación. En el ámbito estatal resulta que por influencia de ambos factores el número total de votantes se amplió en 49.6\%. Si dividimos el universo de municipios en dos, tomando como criterio el promedio estatal, se observa que 76 municipios tuvieron un incremento del número total de votos, inferior al promedio estatal, mientras que 46 crecieron por encima del promedio.

De los 76 municipios cuyos votantes crecieron por debajo del promedio estatal, en 24 se impuso la Alianza por el Cambio, esto representa $31.6 \%$ de dichos municipios. En contrapartida, de los 46 municipios que se encuentran por arriba del promedio estatal, la Alianza por el Cambio triunfó en 29 y la Alianza por México en 2, de manera que las 31 victorias no priístas representaron $67.3 \%$ de estos últimos municipios. Por último, de esas 31 victorias no prístas en municipios con un crecimiento del número de votantes superior a la media, 20 se produjeron en municipios metropolitanos. 


\section{Conclusiones}

A manera de síntesis se puede afirmar que la elección presidencial de 2000, si bien produjo un cambio político de dimensiones considerables, no fue resultado de un cambio en los comportamientos electorales de importancia similar.

Dicho cambio, que se denominó marginal en este último sentido, fue producto de un reagrupamiento de los votos no priístas que generó, a su vez, lo que se dio en llamar en este trabajo como Alianza Virtual.

Más que un cambio en los patrones tradicionales del voto en la entidad, que asocia el voto panista con los altos niveles de urbanismo y al PRI con los altos índices de ruralidad, y al PRD navegando entre ambas tendencias, la nueva configuración electoral fue el resultado de dos elementos fundamentales:

1) La irrupción del voto útil que o bien volcó hacia la Alianza por el Cambio áreas completas consideradas perredistas, o bien redujo la fragmentación del voto no priísta; y

2) La movilización de los nuevos votantes hacia la opción que se creía podía ganar al PRI.

Tal vez esa creencia, que debería estudiarse en otros trabajos, logró en definitiva incentivar la participación de votantes que, de otra manera, como en la elección de gobernador de 1999, se hubieran abstenido.

Con todo, la Alianza Virtual es producto de elementos bastante circunstanciales, por lo que, en la medida en que no se han transformado los patrones del comportamiento electoral en la entidad, se trata de una configuración inestable que podría cambiar, incluso, en el corto plazo. 

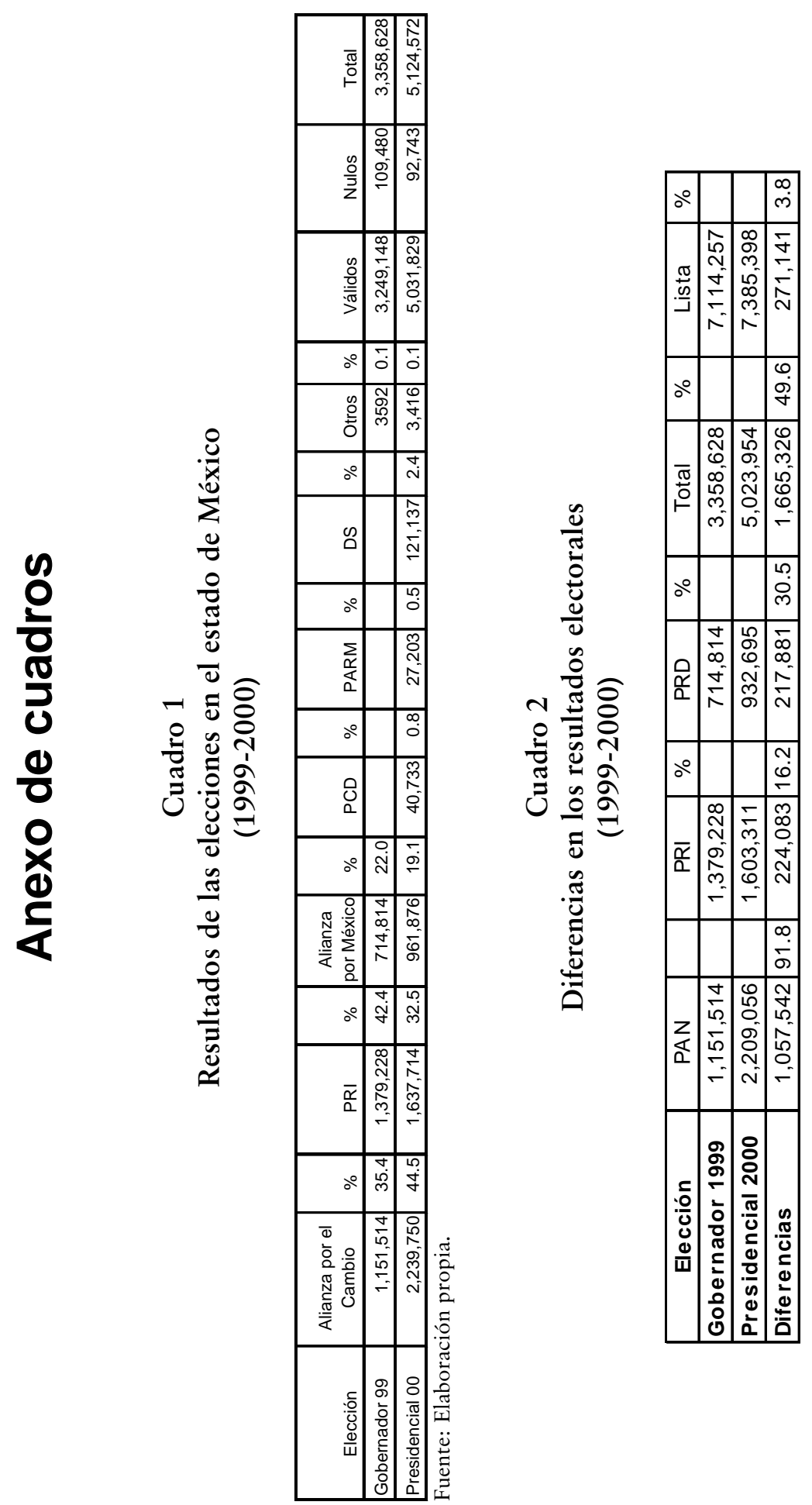


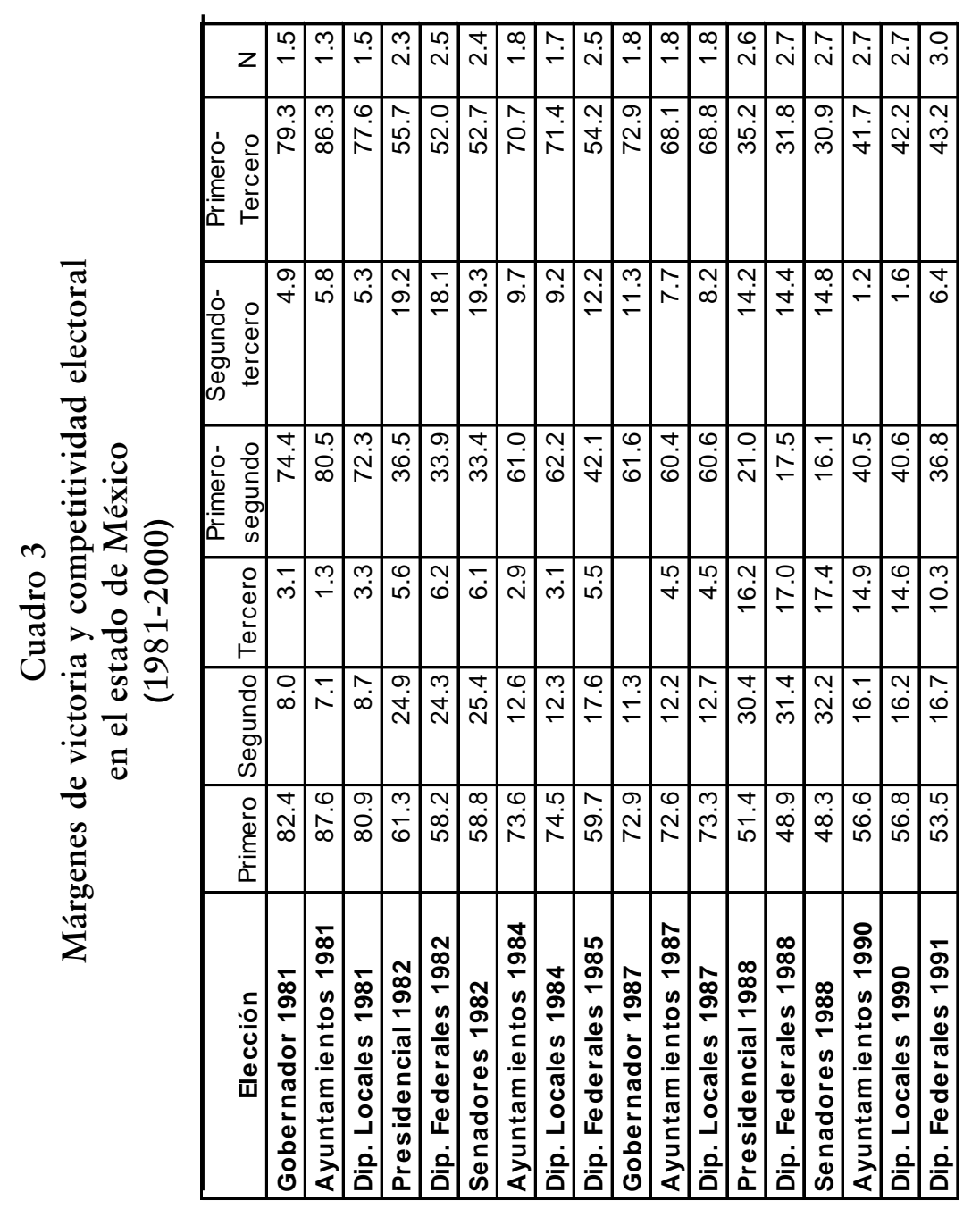




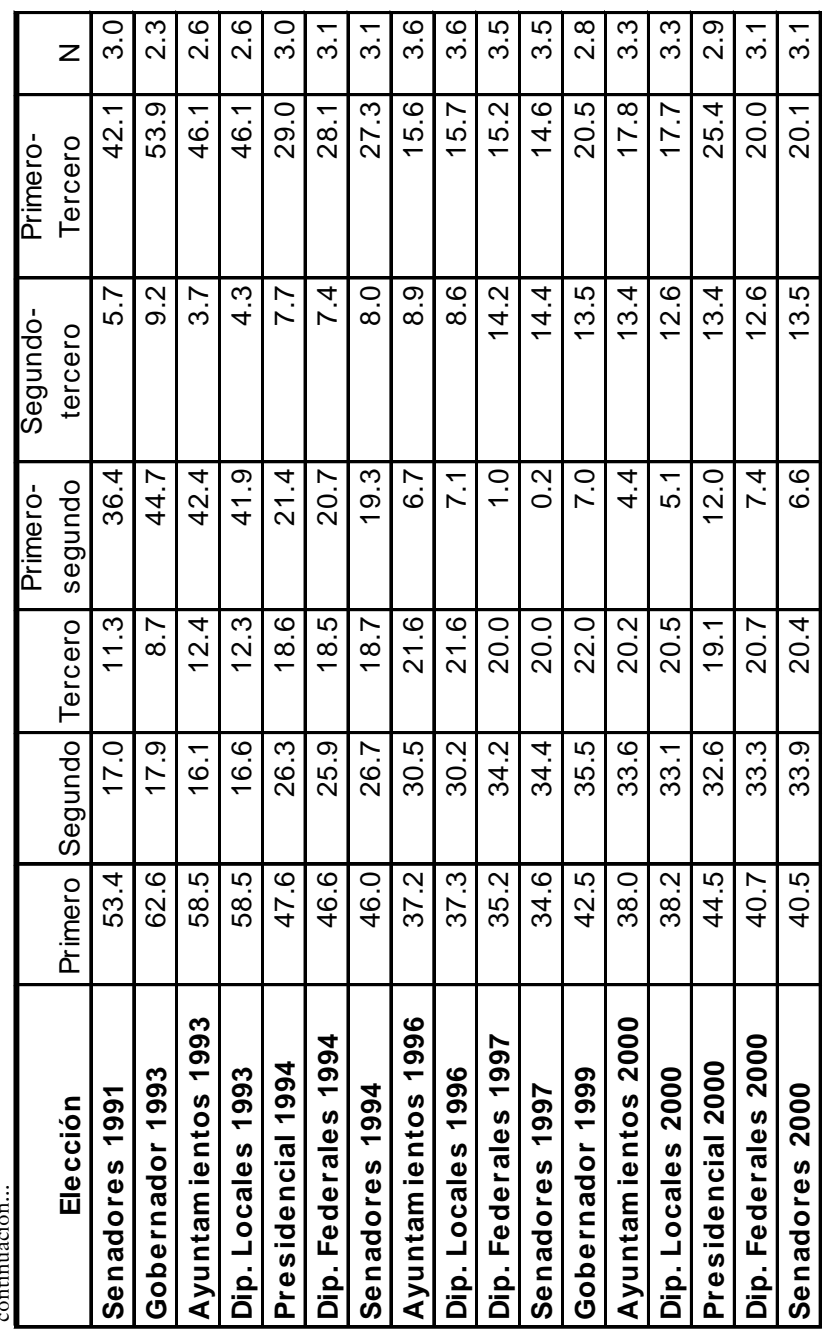




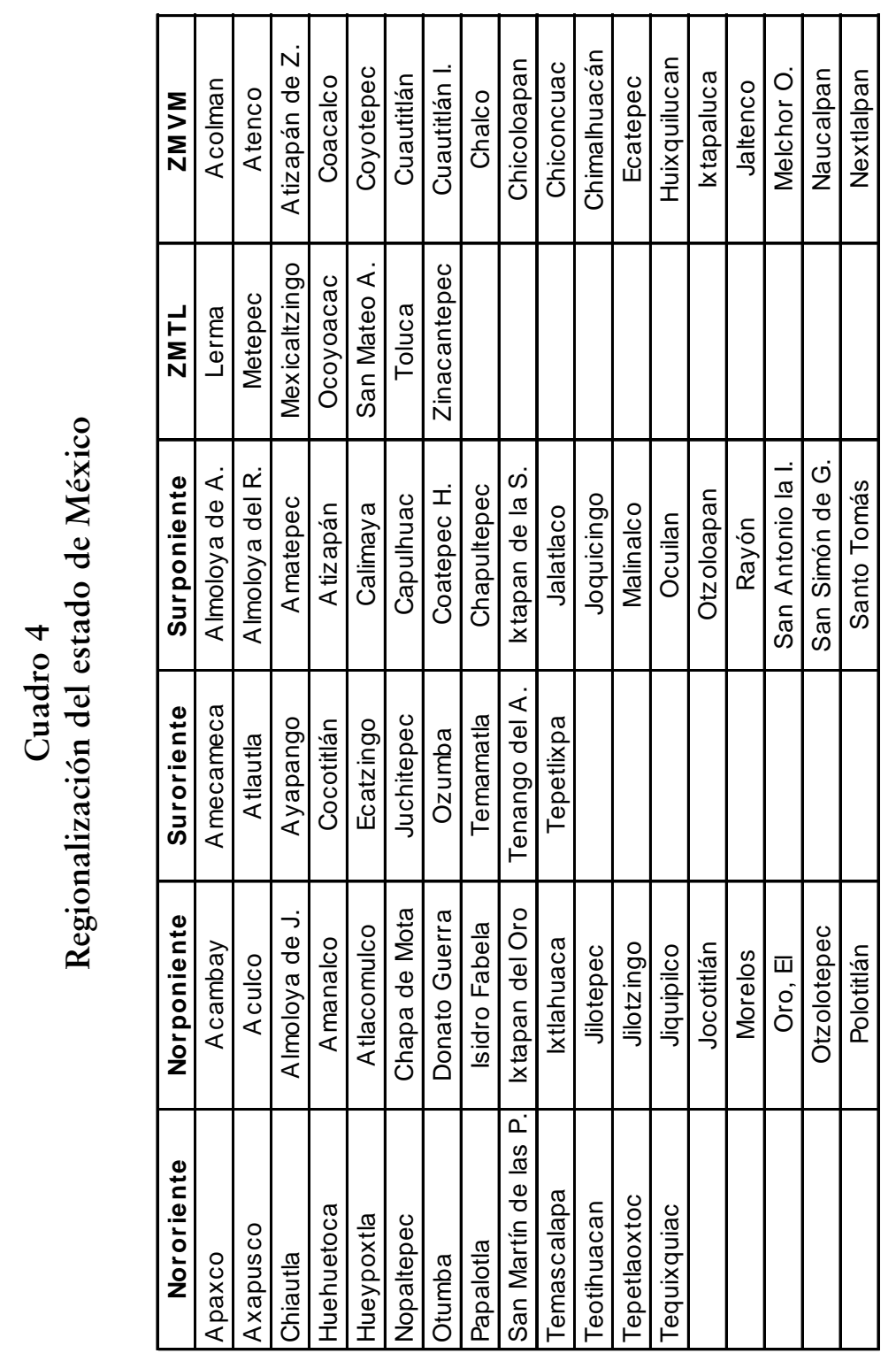




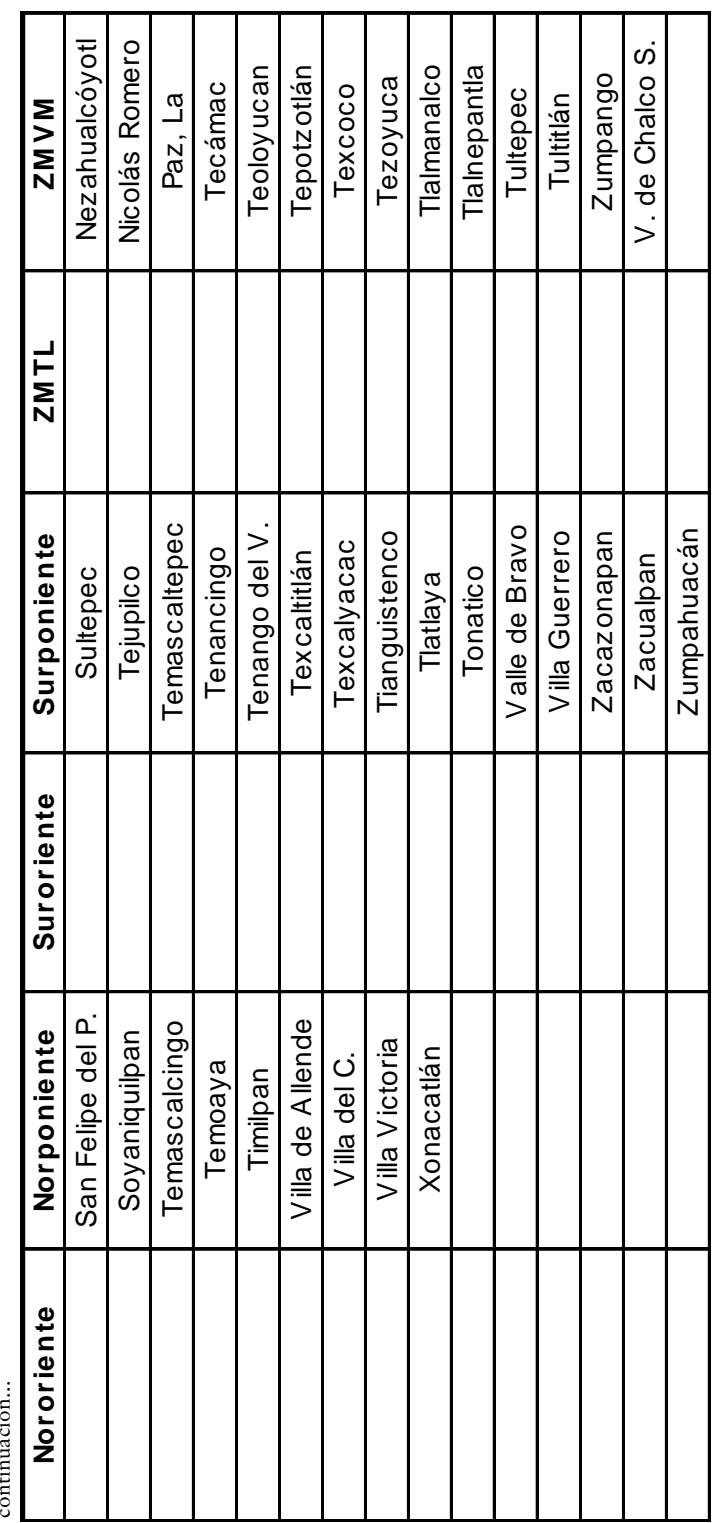




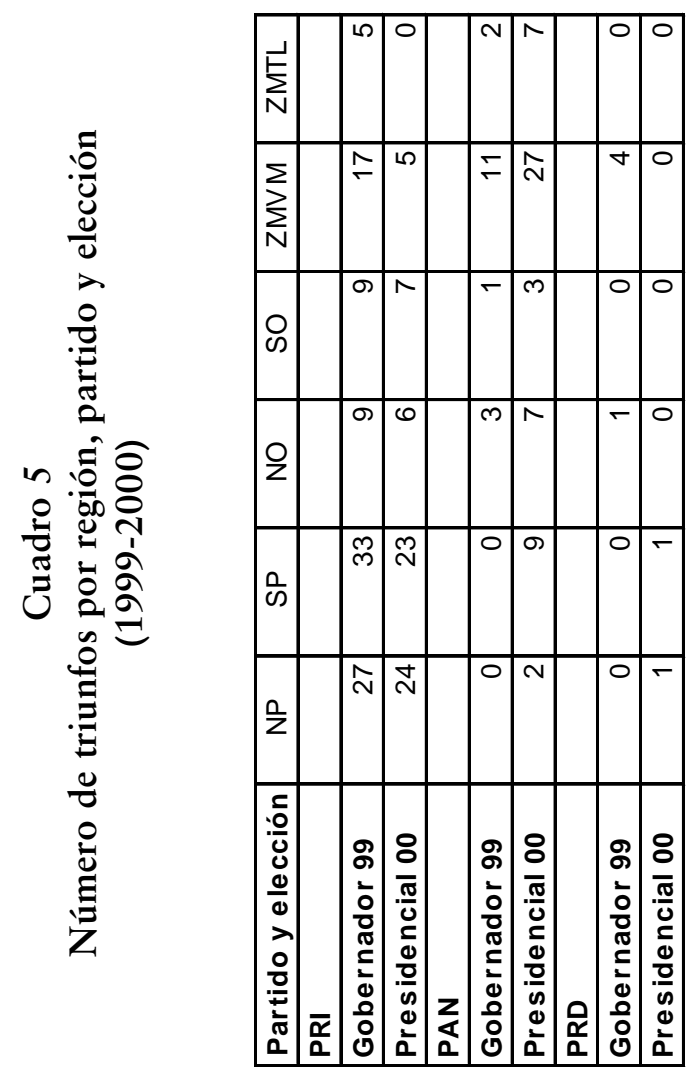




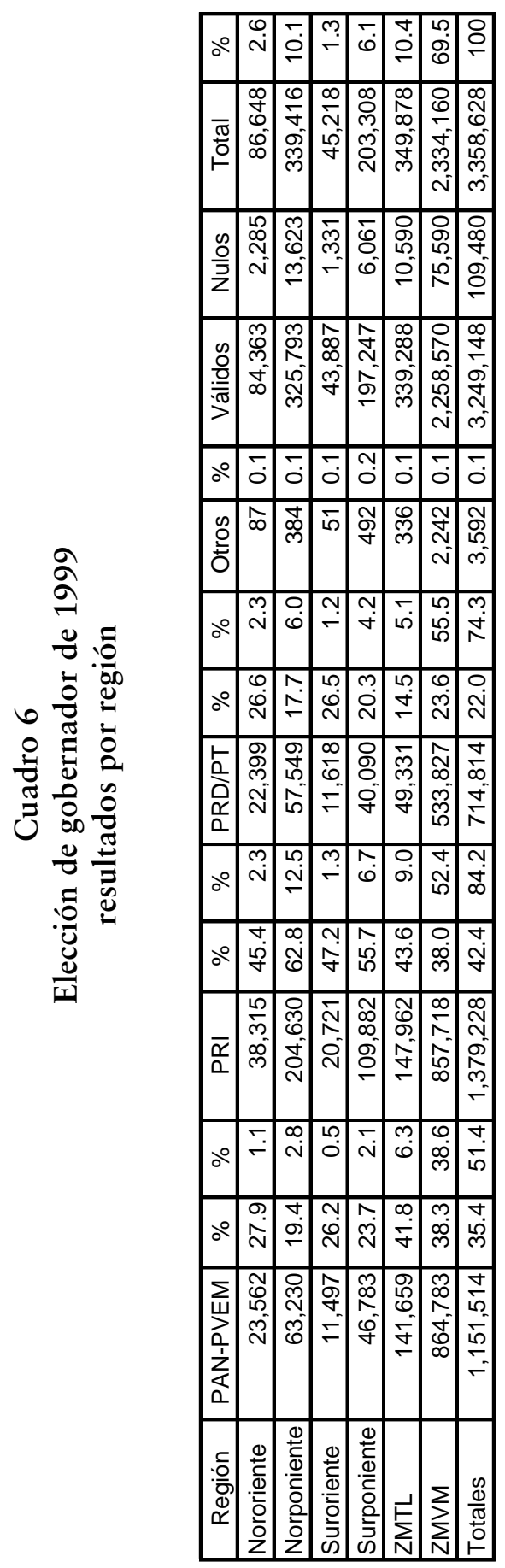




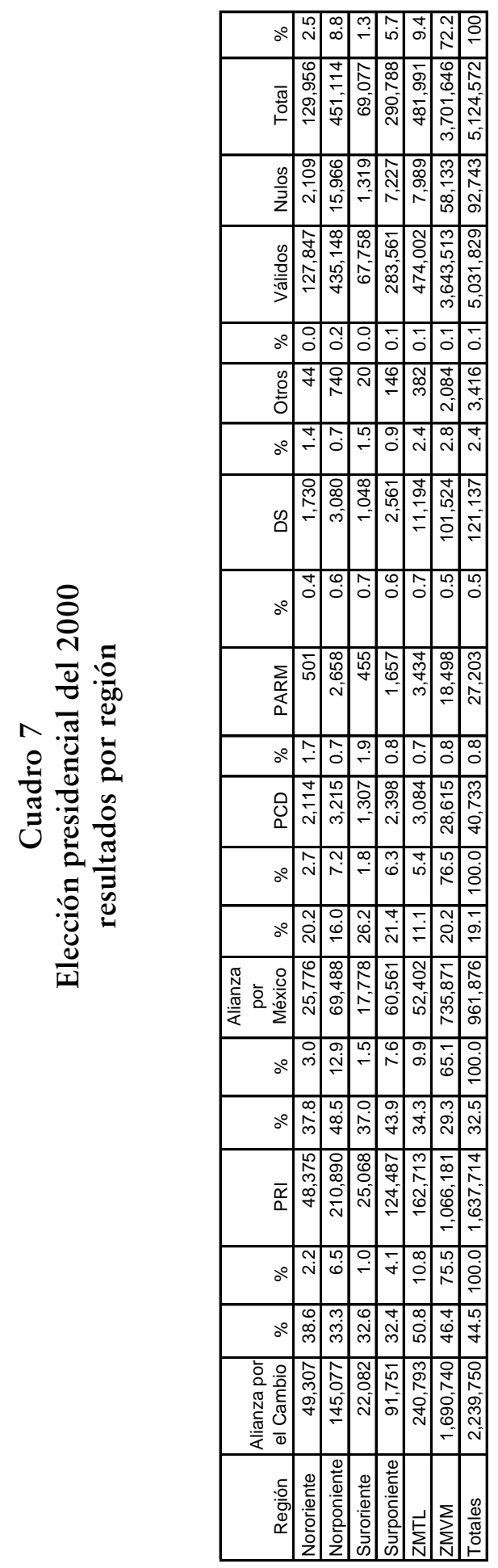




\section{Bibliografía}

Arzuaga, Javier (1999), "El fracaso de las alianzas parciales", ponencia presentada en el XI Congreso Nacional de Estudios Electorales, Sociedad Mexicana de Estudios Electorales/Benemérita Universidad Autónoma de Puebla, Puebla, México, diciembre.

Emmerich, Gustavo Ernesto (1993), “Un ejercicio metodológico a propósito de las elecciones de diputados federales de 1991”, en Gustavo Ernesto Emmerich (coord.), Votos y Mapas. Estudios de geografía electoral en México, UAEM, Toluca.

Emmerich, Gustavo Ernesto (coord.) (1999), El voto ciudadano en el estado de México, UAEM, Toluca.

Molinar, Juan (1991), El tiempo de la legitimidad. Elecciones, autoritarismo y democracia en México, Cal y Arena, México.

Taagepera, Rein y Matthew Shugart (1989), Seat and votes, Yale University Press, New Haven.

Villarreal, Juan Carlos y César David Gómez (2000), "La prospectiva estatal electoral: una explicación estadística”, en Apuntes Electorales, año II, núm. 7, Toluca.

Enviado: 17 de septiembre de 2001 Aceptado: 18 de enero de 2002 